\title{
Fluoride stability in dentifrices stored in schools in a town of northern Brazil
}

\section{Jéssica Bandeira MATIAS(a) Cláudia Said AZEVEDO(a) Hugo Felipe do VALE(b) Maria Augusta Bessa REBELO(a) Flávia COHEN-CARNEIRO(a)}

(a) Universidade Federal do Amazonas - UFAM, School of Dentistry, Manaus, AM, Brazil.

(b) Universidade do Estado do

Amazonas - UEA, School of Health Sciences, Dentistry Course, Manaus, AM, Brazil.
Declaration of Interests: The authors certify that they have no commercial or associative interest that represents a conflict of interest in connection with the manuscript.

Corresponding Author:

Flávia Cohen-Carneiro

E-mail: flaviacohencarneiro@gmail.com

DOI: 10.1590/1807-3107BOR-2015.vol29.0121

Submitted: Dec 12, 2014

Accepted for publication: Jun 12, 2015

Last revision: Aug 31, 2015
Abstract: The aim of this study was to analyze fluoride stability in dentifrices stored during nine months in schools from Careiro da Várzea, State of Amazonas, Brazil. Analysis of total fluoride concentration, total soluble fluoride, and ionic fluoride in the dentifrice samples was performed in four different time periods: at the time of purchase (baseline); after three months, after six months, and after nine months of storage. Fluoride concentration was determined using a specific electrode (Orion 96-09) connected to an ion analyzer (Orion A-720) and calibrated with fluoride standard solutions containing 2.0 to $32.0 \mathrm{ppm}$ F. The results obtained during the measurements were analyzed by analysis of variance (one-way ANOVA), followed by Tukey's test for comparison of the means. After nine months of storage, total soluble fluoride, the active form of fluoride, decreased by $21.9 \%$. As total soluble fluoride was below the minimum required for anticaries efficacy $(1,000 \mathrm{ppm} F)$ in the fourth analysis, it may be concluded that anticaries potential decreased with storage time.

Keywords: Dentifrices; Toothpastes; Fluorides; Dental Caries.

\section{Introduction}

The use of fluoride dentifrices has been considered the main reason for the decline in caries prevalence in the late $20^{\text {th }}$ century. ${ }^{1,2,3}$ However, for a dentifrice to be effective as an anticaries agent, it is necessary that it present at least 1,000 ppm of soluble fluoride. ${ }^{4}$ Currently, $97 \%$ of dentifrices sold in Brazil are fluoridated, and Brazilian law establishes that their fluoride concentration should not exceed 1,500 ppm, regardless of the fluoride salt used, and does not specify its availability or stability over time. ${ }^{5}$

The stability and availability of fluoride in dentifrices can be compromised during their storage and by the interaction of fluoride salt with abrasives in dentifrices. Therefore, sodium fluoride $(\mathrm{NaF})$ dentifrices should not have calcium carbonate as an abrasive because $\mathrm{NaF}$ is ionized when in contact with water, thus releasing fluoride, which reacts with abrasive calcium within the tube, making it insoluble. In monofluorophosphate (MFP)-containing dentifrices, fluoride is covalently bound to phosphate, which is released by the action of phosphatases in the oral cavity. However, MFP undergoes hydrolysis during storage and reacts with calcium carbonate, as described above, hindering the caries preventive action of dentifrices. ${ }^{6}$ In addition, the high temperature accelerates hydrolysis, also acting as a negative factor for the availability of fluoride in dentifrices. ${ }^{7,8}$ 
Some studies have shown that dentifrices sold in Brazil contain an acceptable concentration of soluble fluoride greater than 1,000 ppm at the time of purchase., ${ }^{910}$ However, few studies have studied the effect of storage on the availability of fluoride. ${ }^{8,11}$

An important public health policy, which fosters the development of health promotion activities integrated into the school environment, is now in force in Brazil. The Programa Saúde na Escola (Programa Saúde na Escola - PSE), devised by the Brazilian Ministry of Health and Ministry of Education (Ministério da Saúde - MS e Ministério da Educação - MEC), was implemented in 2007, allowing for educational practices in oral health and toothbrushing with fluoridated dentifrices in schools. ${ }^{12}$ This long-term policy can achieve important results in the control of caries among Brazilian schoolchildren, as with similar interventions developed in other countries. ${ }^{13,14,15}$ However, the effectiveness of the program is a cause for concern because of the storage of necessary supplies.

Taking into consideration the public logistics network (bidding, purchase, and distribution of inputs to schools), we can assume that the products necessary for the School Health Program, including fluoride dentifrices, are purchased in large amounts and stored in schools to meet the demand during educational activities throughout the year. This logistics could have a negative impact on the effectiveness of dentifrices that are stored for long periods of time. Therefore, this study aimed to analyze total fluoride and total soluble fluoride concentrations in dentifrices stored at the schools included in the PSE, located in Careiro da Várzea, a town in the State of Amazonas, northern Brazil, over a period of nine months.

\section{Methodology}

This prospective study consisted of the analysis of eight dentifrices from three different batches (batch 1 : 3060BR121I/Expiration date: 03/16; batch 2:3040BR121I/ Expiration date: 02/16; batch 3: 2311BR121I/Expiration date: 11/15). The samples were coded with Arabic numbers. All the dentifrices belonged to Sorriso ${ }^{\circledR}$ (Colgate Palmolive Industrial Ltda., São Bernardo do Campo, Brazil) and had been manufactured three years before the expiration date informed. According to the manufacturer, they contained 1,450 ppm fluoride in the form of MFP, and calcium carbonate as abrasive agent.
The tubes of toothpaste were stored in a refrigerated room (minimum temperature: $18.5^{\circ} \mathrm{C}$; maximum temperature: $25.3^{\circ} \mathrm{C}$; mean temperature: $21.8^{\circ} \mathrm{C}$ ) at the selected schools, and were not opened until the moment of analysis, which occurred on four separate occasions: at the time of purchase (baseline), after three months, after six months, and after nine months of storage. The samples were collected from September to December 2013, and from March to June 2014.

Three forms of the available ion were analyzed to determine fluoride concentration: ionic fluoride (F-), total soluble fluoride (TSF), and total fluoride (TF).

The analyses were performed in duplicate, according to the protocol used by Cury et al. ${ }^{9}$ One hundred milligrams of dentifrice was weighed with the aid of a high precision digital electronic balance, and then the dentifrice sample was homogenized with $10 \mathrm{~mL}$ of deionized water. After that, $0.20 \mathrm{~mL}$ of the suspension was transferred into a polypropylene tube for the analysis of TF. The remainder of the suspension was centrifuged (3,000 rpm for 10 minutes) and $0.20 \mathrm{~mL}$ of the supernatant was transferred in duplicate into polypropylene tubes for the analysis of TSF and F-. For the determination of TF and TSF, $0.20 \mathrm{~mL}$ of $2.0 \mathrm{M} \mathrm{HCl}$ was added to the tubes, and after 1 h of hydrolysis at $45^{\circ} \mathrm{C}$, the solution was neutralized with $0.40 \mathrm{~mL}$ of $1.0 \mathrm{M} \mathrm{NaOH}$ and $0.80 \mathrm{~mL}$ of TISAB II (1.0 M acetate buffer, $\mathrm{pH} 5.0$, containing $1.0 \mathrm{M} \mathrm{NaCl}$ and $0.4 \%$ CDTA). For the determination of F-, $0.40 \mathrm{~mL}$ of 1.0 $\mathrm{M} \mathrm{NaOH}, 0.80 \mathrm{~mL}$ of TISAB II, and $0.20 \mathrm{~mL}$ of $2.0 \mathrm{M}$ $\mathrm{HCl}$ were added. The determination of the ionizable fluoride concentration was obtained by applying the formula: MFP = TSF - F-. The following formula was applied to determine the concentration of insoluble fluoride (Fins): Fins = TF - (F- + MFP). The analyses were carried out using a fluoride-specific electrode (Orion model 96-09, Orion Research, Cambridge, USA) coupled to an ion analyzer (Orion A-720) and calibrated with fluoride standard solutions containing 2.0, 4.0, 8.0, 16.0, and 32.0 ppm F, prepared with the same reagents used for the samples.

The statistical analyses compared the changes in fluoride concentration over time. After checking the normality of data distribution by the Shapiro-Wilk test, the means were compared by analysis of variance (repeated measures ANOVA), followed by the Tukey's 
test, setting the significance level at 5\%. The SAS 9.1 software (The SAS Institute, Cary, USA) was used for all analyses.

\section{Results}

The mean fluoride concentrations are shown in Table. Total fluoride showed no significant reduction between baseline and nine months of evaluation. However, TSF decreased by $21.9 \%$ after nine months of storage $(\mathrm{p}<0.05)$.

Table also demonstrates the decrease of soluble fluoride with the increase of storage time. After nine months of storage, TSF had concentrations below $1,000 \mathrm{ppm} F$. Conversely, insoluble fluoride increased about $146 \%$ after nine months of storage.

\section{Discussion}

Fluoride dentifrices were considered to be the most common reason for the decline in caries prevalence in many countries in the late $20^{\text {th }}$ century. Therefore, fluoride dentifrices became the main method for caries prevention, since they combine biofilm removal with constant exposure of the oral cavity to fluoride. However, in order to be effective against caries, fluoride must be in its active form and be stable during storage time. ${ }^{16}$

The present study analyzed the ionic concentration of fluoride in Sorriso ${ }^{\circledR}$ dentifrices, which contain ionizable fluoride in the form of MFP and calcium carbonate as abrasive agent, in addition to $1,450 \mathrm{ppm} F$. The results showed that, in nine months, total fluoride concentration did not achieve a significant reduction. On the other hand, TSF showed concentrations below 1,000 ppm $\mathrm{F}$ after nine months of storage. This is considered the minimum concentration of chemically soluble fluoride required to obtain anticaries effectiveness. ${ }^{4}$
The reduction in the concentration of soluble fluoride may be attributed to the reaction that occurs within the dentifrice tube over time. MFP is subjected to hydrolysis, and that is when the fluoride covalently bound to the phosphate is released and reacts with abrasive calcium (calcium carbonate) present in the dentifrice, resulting in calcium fluoride, and increasing the concentration of insoluble fluoride.,11 Another factor that contributes to the reduction of TSF is temperature, since studies have shown that an increase in temperature accelerates hydrolysis. ${ }^{7,8}$

Few studies have examined the availability and stability of fluoride in dentifrices stored over time. A study by Hashizume et al. ${ }^{11}$ evaluated the most widely sold dentifrices in Japan at the time of purchase and after one year of storage at an average temperature of $21.8^{\circ} \mathrm{C}$. All dentifrices tested had an initial TSF concentration below $1,000 \mathrm{ppm}$, with a reduction of approximately $15 \%$ of this concentration throughout one year for dentifrices whose composition was similar to that of toothpastes used in the present study (MFP + calcium carbonate). However, in Japan, the legislation prohibits the marketing of dentifrice with more than 1,000 ppm of total fluoride. That ensures dentifrices follow the concentrations stipulated by law, even though the anticaries potential is reduced. The reduction in the concentration of soluble fluoride was also demonstrated in the study of Conde et al. ${ }^{8}$ Their study evaluated dentifrices purchased, stored, and consumed in Manaus, Brazil, during one year and under two different temperature conditions: non-refrigerated environment (average temperature: $28.9^{\circ} \mathrm{C}$ ) and refrigerated environment (average temperature: $26.3^{\circ} \mathrm{C}$ ). In the study of Conde et al., ${ }^{8}$ dentifrices of the Sorriso ${ }^{\circledast}$ brand revealed the highest

Table. Concentration (ppm F) of total fluoride, total soluble fluoride, ionic fluoride, and ionizable fluoride; and the percentage of insoluble fluoride (mean $\pm \mathrm{SD} ; \mathrm{n}=8$ ) found in dentifrices stored in Careiro da Várzea-AM over time.

\begin{tabular}{lcccc}
\hline \multirow{2}{*}{ Variable } & \multicolumn{4}{c}{ Time } \\
\cline { 2 - 5 } & Baseline & 3 months & 6 months & 9 months \\
\hline TF $($ ppm F) & $1,409.20(45.03) a$ & $1,366.25(12.11) a$ & $1218.19(42.07) b$ & $1,354.84(58.57) \mathrm{a}$ \\
TSF (ppm F) & $1,260.15(84.01) a$ & $1,111.14(46.93) \mathrm{b}$ & $1014.55(17.89) \mathrm{c}$ & $983.21(36.38) \mathrm{c}$ \\
F- (ppm F) & $1,40.74(16.52) \mathrm{a}$ & $131.25(15.62) \mathrm{a}$ & $121.77(13.10) \mathrm{a}$ & $121.53(10.56) \mathrm{a}$ \\
MFP (ppm F) & $1,119.42(98.08) \mathrm{a}$ & $979.86(60.72) \mathrm{b}$ & $892.79(25.50) \mathrm{bc}$ & $861.68(40.49) \mathrm{c}$ \\
Fins (\%) & $10.68(5.91) \mathrm{c}$ & $18.64(3.71) \mathrm{b}$ & $16.60(4.00) \mathrm{b}$ & $27.36(3.39) \mathrm{a}$ \\
\hline
\end{tabular}

Different lowercase letters in a row represent statistical differences in repeated measures ANOVA/Tukey's test $(p<0.05)$. 
decrease in TSF when stored under non-refrigerated conditions (approximately 30\%) compared to refrigerated conditions (approximately $24 \%$ ).

These aspects related to storage conditions - time and temperature - had a negative impact on the effectiveness of the analyzed dentifrices, raising concerns about the effectiveness of dentifrices purchased on a large scale and stored for a long time. Due to the logistics of public bidding and the purchase and distribution of fluoride dentifrices to the schools included in the School Health Program, it is assumed that dentifrices are purchased and stored on a large scale to be used throughout the year, and some of them, under unfavorable storage conditions. Despite the reduction in the concentration of soluble fluoride in dentifrices, they would still comply with the national legislation because this regulates only the maximum fluoride concentration, not specifying the need to maintain a minimum concentration of soluble fluoride during their shelf life. ${ }^{5}$

\section{Conclusion}

It may be concluded from the fourth analysis of dentifrices stored at schools in Careiro da Várzea that the anticaries potential was reduced, as they did not present the minimum concentration of TSF necessary for effectiveness (1,000 ppm F).

\section{References}

1. Marinho VCC, Higgins JPT, Logan S, Sheiham A. Fluoride toothpastes for preventing dental caries in children and adolescents. Cochrane Database Syst Rev. 2003;(1):CD002278.

2. Cury JA, Tenuta LMA, Ribeiro CCC, Paes Leme, AF. The importance of fluoride dentifrices to the current dental caries prevalence in Brazil. Braz Dent J. 2004;15(3):167-74. doi:10.1590/S0103-64402004000300001

3. Santos APP, Nadanovsky P, Oliveira BH. A systematic review and meta-analysis of the effects of fluoride toothpastes on the prevention of dental caries in the primary dentition of preschool children. Community Dent Oral Epidemiol. 2013;41(1):1-12. doi:10.1111/j.1600-0528.2012.00708.x

4. Walsh T, Worthington HV, Glenny AM et al. Fluoride toothpaste prevents caries in children and adolescents at fluoride concentrations of $1000 \mathrm{ppm}$ and above. Evid Based Dent. 2010;11(1):6-7. doi:10.1038/sj.ebd.6400698
It is suggested that storage conditions - time and temperature - are important factors that should be considered for the effectiveness of fluoride dentifrices used in school programs. Therefore, the public logistics should be optimized so that storage time at the schools do not exceed six months. Furthermore, the results indicate that Resolution No. 79 of August 28, 2000, ${ }^{5}$ which establishes the maximum fluoride concentration (1,500 ppm), but does not specify quality, should be reviewed.

\section{Acknowledgments}

The authors thank Research Foundation of the State of Amazonas (Fundação de Amparo à Pesquisa do Estado do Amazonas - FAPEAM) - for the research fellowship (PIBIC GDP-S 0060/2013) and Brazilian National Council for Scientific and Technological Development (Conselho Nacional de Desenvolvimento Científico e Tecnológico - CNPq) - for financial support (grant No.10/2012MCTI / CNPq / MS-SCTIE-DECIT-Research into Oral Health). We also thank Ronaldo Vitoriano Bastos for the technical assistance at the Research Laboratory at the School of Dentistry/UFAM and Dr. Jaime Aparecido Cury (FOP/UNICAMP) for providing the spreadsheet for calculation of fluoride concentrations and for performing the second analysis of the dentifrices in Careiro da Várzea.

5. Ministério da Saúde (BR), Secretaria Nacional de Vigilância Sanitária. Resolução RDC no 79, de 28 de agosto de 2000. Diário Oficial União; 2000 Aug 31;169:1415-537.

6. Tenuta LMA, Cury JA. Fluoreto: da ciência à prática clínica. In: Assed, S. Odontopediatria: bases científicas para a prática clínica. São Paulo: Artes Médicas; 2005. p. 113-52.

7. Tabchoury CPM,Cury JA. Estudo de condições deenvelhecimento precoce de dentifrícios para prever o comportamento do flúor em condições ambientais. Rev Bras Farm. 1994;75(3):67-71.

8. Conde NCO, Rebelo MAB, Cury JA. Evaluation of the fluoride stability of dentifrices sold in Manaus, AM, Brazil. Pesq Odontol Bras. 2003;17(3):247-53. doi:10.1590/S1517-74912003000300009

9. Cury JA, Oliveira MJL, Martins CC, Tenuta LMA, Paiva SM. Available fluoride in toothpastes used by Brazilian children. Braz Dent J. 2010;21(5):396-400. doi:10.1590/S0103-64402010000500003 
10. Ricomini Filho AP, Tenuta LMA, Fernandes FSF, Bissoto AF, Kusano SC, Cury JA. Fluoride concentration in the top-selling Brazilian toothpastes purchased at different regions. Braz Dent J. 2012;23(1):45-8. doi:10.1590/S0103-64402012000100008

11. Hashizume LN, Lima YBO, Kawaguchi Y, Cury JA. Fluoride availability and stability of Japanese dentifrices. J Oral Sci. 2003;45(4):193-9. doi:10.2334/josnusd.45.193

12. Ministérios da Saúde e da Educação (BR). Decreto $n^{\circ} 6.286$, de 5 de dezembro de 2007. Institui o Programa Saúde na Escola - PSE, e dá outras providências. Diário Oficial União. 2007 Dec 6.

13. Andruškevičiene V, MilčiuvieneS, Bendoraitiene E, Saldunaite $\mathrm{K}$, Vasiliauskiene I, Slabsinskiene E et al. Oral health status and effectiveness of caries prevention programme in
Kindergartens in Kaunas City (Lithuania). Oral Health Prev Dent. 2008;6(4):343-8. doi:10.3290/j.ohpd.a14181

14. Macpherson LMD, Anopa Y, Conway DI, McMahon AD. National supervised toothbrushing program and dental decay in Scotland. J Dent Res. 2013;92(2):109-13. doi:10.1177/0022034512470690

15. Monse B, Benzian H, Naliponguit E, Belizario V, Schratz A, van Palenstein Helderman W. The Fit for School health outcome study - a longitudinal survey to assess health impacts of an integrated school health programme in the Philippines. BMC Public Health. 2013;13:256. doi:10.1186/1471-2458-13-256

16. Cury JA, Tenuta LMA. Evidence-based recommendation on toothpaste use. Braz Oral Res. 2014;28(Spec Iss ):1-7. doi:10.1590/S1806-83242014.50000001 